\title{
Primary Gastric Lymphoma: Conservative Treatment Modality Is Not Inferior to Surgery for Early-Stage Disease
}

\author{
Fatih Selçukbiricik, ${ }^{1}$ Deniz Tural, ${ }^{1}$ Olgun Elicin, ${ }^{2}$ Selin Berk, ${ }^{3}$ Mustafa Özgüroğlu, ${ }^{1}$ \\ Nuran Bese, ${ }^{2}$ and Burhan Ferhanoglu ${ }^{3}$ \\ ${ }^{1}$ Division of Medical Oncology, Department of Internal Medicine, Cerrahpasa Medical Faculty, Istanbul University, \\ 34098 Istanbul, Turkey \\ ${ }^{2}$ Department of Radiation Oncology, Cerrahpasa Medical Faculty, Istanbul University, 34098 Istanbul, Turkey \\ ${ }^{3}$ Division of Medical Oncology, Department of Internal Medicine, Cerrahpasa Medical Faculty, Istanbul University, \\ 34098 Istanbul, Turkey \\ Correspondence should be addressed to Deniz Tural, deniztural@gmail.com
}

Received 10 July 2012; Accepted 27 July 2012

Academic Editors: N. Fujimoto, O. Hansen, and V. Lorusso

Copyright (๑) 2012 Fatih Selçukbiricik et al. This is an open access article distributed under the Creative Commons Attribution License, which permits unrestricted use, distribution, and reproduction in any medium, provided the original work is properly cited.

Objectives. The aim of this study was to evaluate clinical characteristics, prognostic factors, survival rates, and treatment modalities in patients with primary gastric lymphoma (PGL). Methods. We retrospectively reviewed and analyzed data from patients treated for PGL in our clinic from 1998 through 2010. Staging was performed using the Lugano Staging System. Overall and diseasefree survival (OS and DFS) were calculated from the date of diagnosis. Results. We identified 79 patients. Thirty-seven patients $(47 \%)$ were male. The median age at presentation was 57 (18-85) years. The median follow-up time was 41 (9-52) months. Thirty patients $(38 \%)$ underwent surgery, $74(92 \%)$ received chemotherapy, and $18(23 \%)$ received radiotherapy. The five-year OS and DFS rates were $91.2 \%$ and $83.9 \%$, respectively, in patients with stage I/II or IIE disease and $70.6 \%$ and $65.5 \%$, respectively, in patients with stage IV disease ( $P=0.02$ for both rates). Treatment modality (surgical or conservative) had no impact on OS or DFS in early stages. In a multivariate analysis, poor performance status, advanced stage, and high LDH levels were significant bad prognostic factors for DFS, while advanced stage, poor performance status, and age $>60$ years were significant bad prognostic factors for OS. Conclusion. Surgery provides no advantage for survival over conservative treatment; thus, conservative treatment modalities should be preferred initially at early stages of PGL.

\section{Introduction}

Approximately $40 \%$ of all non-Hodgkin lymphomas (NHLs) occur in extranodal locations. The gastrointestinal tract is the predominant site of extranodal NHL [1]. Primary NHLs of the gastrointestinal tract are rare, accounting for only $1-4 \%$ of malignancies arising in that area [2]. The stomach is the most common site of NHL [3]. In two large studies, primary gastric lymphoma (PGL) accounted for 68$75 \%$ of patients with primary gastrointestinal tract NHL $[4,5]$. There was a slight predominance of males with PGL (male: and female, 1.1:1) [4]. PGL diagnoses reached their peak incidence in individuals between the ages of 50 to 60 years. The most common presenting symptoms included epigastric pain, epigastric discomfort, anorexia, weight loss, nausea, vomiting, and gastrointestinal bleeding. Systemic B symptoms occurred in $12 \%$ of PGL patients $[4,5]$.

Extranodal marginal zone B-cell lymphoma of the mucosa associated lymphoid tissue (MALT) type accounted for $40-48 \%$ of PGL cases $[4,5]$. According to pathological classification, PGL comprises low-grade and aggressive types. Surgery was the initial treatment for PGL in the past. Currently, high-grade stage I/II PGL can be treated with chemotherapy followed by radiotherapy, and advanced stage PGL is usually treated with chemotherapy only $[6,7]$. Surgery is reserved for complicated disease and residual disease after conservative treatment [6]. Low-grade stage I/II Helicobacter pylori (+) MALT lymphomas can be treated 
with antibiotic therapy. Treatment failure with $H$. pylori eradication can be managed with radiation therapy [6].

In this study, we aimed to determine the clinical characteristics of patients with PGL who were referred to our clinic over the last 12 years. We also aimed to evaluate patient survival and prognostic factors affecting survival and the effect of combined surgical and conservative treatment.

\section{Materials and Methods}

2.1. Study Design and Population. We retrospectively reviewed and analyzed the data of patients treated for PGL in our clinic (Istanbul University, Cerrahpasa Medical Faculty, Department of Internal Medicine, Division of Medical Oncology) from 1998 through 2010. All patients with MALT lymphoma who did not respond to antibiotic therapy for $H$. pylori eradication or who demonstrated relapse during followup were included in the study. Approval from the local ethics committee and informed consent of the patients or their next of kin were obtained prior to the study.

2.2. Study Procedures. The following characteristics or results were recorded for each patient: medical history, physical examination, biochemistry, computed tomography (CT) of the thorax and abdomen, multiple gastroscopic biopsies of the upper and lower gastrointestinal tract, examination of Waldeyer's ring, and bone marrow biopsy. Disease staging was performed using the Lugano Staging System [7]. Histological diagnosis was determined by skilled hematopathologists. Histological subtype classification was determined according to the World Health Organization criteria [8]. Poor performance status was defined using the Karnofsky scale $(<80)$. A blood lactate dehydrogenase (LDH) level of $\geq 240 \mathrm{mg} / \mathrm{dL}$ was accepted as high (normal range, 0$240 \mathrm{mg} / \mathrm{dL}$ ). Conservative (e.g., chemotherapy, radiotherapy) or surgical treatments applied to each patient were recorded.

2.3. Study Endpoints. Overall and disease-free survival (OS and DFS) were the primary endpoints. OS and DFS were calculated from the date of diagnosis. DFS was defined as the time until disease recurrence, progression, or death from disease or chemotherapy related toxicity, whichever occurred first. OS was defined as the time of death from any cause. The effects of age, sex, LDH level, tumor stage and pathological subtype, performance status, presenting symptoms, and tumor treatment modality on OS and DFS were evaluated.

2.4. Statistical Analysis. Categorical and continuous variables were summarized using descriptive statistics (e.g., median, range, frequency, and percentage) and compared with chisquare and Mann-Whitney $U$ tests, respectively. DFS and OS rates were estimated by the Kaplan-Meier method. The effects of clinical variables on DFS and OS were assessed with a univariate analysis. The log-rank test was used to compare curves for the univariate analysis. A Cox proportional hazards model was used to assess independent prognostic
TABLe 1: Predominant site of primary gastric lymphoma and symptoms at diagnosis $(n=79)$.

\begin{tabular}{lcc}
\hline & $n$ & $\%$ \\
\hline Predominant site of gastric lymphoma & & \\
$\quad$ Corpus & 28 & 35 \\
Antrum & 26 & 33 \\
Cardia & 7 & 9 \\
Fundus & 2 & 3 \\
Multiple site & 5 & 6 \\
Unknown & 11 & 14 \\
Symptoms & & \\
Abdominal pain and dyspepsia & 55 & 70 \\
Weight loss, fever, night sweat & 42 & 53 \\
Nausea and vomiting & 13 & 17 \\
Weakness & 11 & 14 \\
Gastrointestinal bleeding & 8 & 10 \\
\hline
\end{tabular}

factors for DFS and OS. All analyses were performed using SPSS 15.0 (SPSS Inc., Chicago, IL, USA) software. The statistical level of significance was defined as $P<0.05$.

\section{Results}

3.1. Clinical and Pathological Characteristics. Data from 79 patients with PGL were retrospectively analyzed. The corpus and antrum of the stomach were the predominant sites of PGL. Abdominal pain and dyspepsia were the main symptoms of presentation in $70 \%$ of patients, followed by weight loss, fever, or night sweats (B symptoms) in 53\% and nausea and vomiting in $10 \%$ of patients (Table 1 ).

The median age at presentation was 57 years (range, 18-85 years) and 37 patients (47\%) were male. Of the 79 patients, $63(79 \%)$ were classified as having non-MALT and $16(21 \%)$ as having MALT lymphoma. Eleven patients had a poor performance status, according to the Karnofsky scale $(<80)$. Of the 79 total patients, $57(81 \%)$ had stage I/II or IIE disease and $22(19 \%)$ had stage IV disease. The clinical characteristics of the patients with respect to MALT status are shown in Table 2.

3.2. Treatment Modalities and Response. The treatment modalities applied to patients with respect to MALT status and stage of disease are shown in Table 3. Thirty patients (38\%) underwent surgery, 74 (92\%) received chemotherapy, and $18(23 \%)$ received radiotherapy. The most common type of surgical treatment procedure was total gastrectomy and lymph node dissection either as combined or single treatment modalities. The most common chemotherapy regimen was cyclophoshamide, doxorubicine, vincristine, and prednisolone (CHOP) (70\% of patients). Fifty percent of patients were administered six cycles of chemotherapy, 25\% were administered three cycles, and 25\% were administered four or five cycles. Patients who received radiotherapy were treated with extended-field irradiation to the upper and middle parts of the abdomen with 30-45 Gy. 
TABLE 2: Clinical characteristics of study patients $(n=79)$.

\begin{tabular}{lccc}
\hline & & $\begin{array}{c}\text { Non-MALT } \\
(n=63)\end{array}$ & $\begin{array}{c}\text { MALT } \\
(n=16)\end{array}$ \\
\hline $\begin{array}{l}\text { Age } \\
\text { (years, median (range) })\end{array}$ & Male & $28(45 \%)$ & $9(56 \%)$ \\
Gender $(n(\%))$ & Female & $34(55 \%)$ & $7(44 \%)$ \\
& I/II, IIE & $44(71 \%)$ & $13(81 \%)$ \\
Stage $(n(\%))$ & IV & $19(29 \%)$ & $3(19 \%)$ \\
& $\geq 80$ & $56(89 \%)$ & $12(75 \%)$ \\
$\begin{array}{l}\text { Karnofsky } \\
\text { performance status }\end{array}$ & $<80$ & $7(11 \%)$ & $4(25 \%)$ \\
& $>240$ mg & $26(42 \%)$ & $9(56 \%)$ \\
LDH level $(n(\%))$ & Normal range & $28(45 \%)$ & $5(31 \%)$ \\
& Unknown & $9(13 \%)$ & $2(13 \%)$ \\
\hline
\end{tabular}

MALT: mucosa associated lymphoid tissue, LDH: lactate dehydrogenase.

TABle 3: Treatment modality applied for study patients $(n=79)$.

\begin{tabular}{|c|c|c|c|c|}
\hline & \multicolumn{2}{|c|}{ Non-MALT $(n=63)$} & \multicolumn{2}{|c|}{ MALT $(n=16)$} \\
\hline & $\begin{array}{l}\text { Stage } \\
\text { I/II, IIE }\end{array}$ & Stage IV & $\begin{array}{l}\text { Stage } \\
\text { I/II, IIE }\end{array}$ & Stage IV \\
\hline Conservative & $27(63 \%)$ & $12(67 \%)$ & $7(54 \%)$ & $3(100 \%)$ \\
\hline $\mathrm{CT}$ & 22 & 10 & 3 & 3 \\
\hline $\mathrm{CT}+\mathrm{RT}$ & 5 & 2 & 1 & \\
\hline RT & & & 3 & \\
\hline Nonconservative & $17(37 \%)$ & $7(33 \%)$ & $6(46 \%)$ & 0 \\
\hline Surgery + CT & 16 & 6 & 4 & \\
\hline Surgery $+\mathrm{CT}+\mathrm{RT}$ & 1 & 1 & 2 & \\
\hline
\end{tabular}

MALT: mucosa associated lymphoid tissue, CT: chemotherapy, and RT: radiotherapy.

3.3. Survival and Univariate Analysis. All 79 patients were enrolled into our survival analysis study. The median followup was 41 months (range, 9-52 months). The fiveyear OS and DFS, which were estimated by using the KaplanMeier method, were $83.1 \%$ and $78.6 \%$, respectively (Figures 1 and 2). In patients with stage I/II or IIE presentation, the five-year OS and DFS rates were $91.2 \%$ and $83.9 \%$, respectively. The five-year OS and DFS in patients with stage IV disease were $70.6 \%$ and $65.5 \%$, respectively. Both OS and DFS were significantly lower in those with advanced stage disease $(P=0.002$ and $P=0.02$, resp. $)$. For MALT lymphoma patients, the five-year OS and DFS rates were $91.2 \%$ and $81.3 \%$, respectively. OS and DFS were not different between MALT and non-MALT groups $(P=0.38$ and $P=0.57$, resp.). Poor performance status was significantly associated with lower DFS and OS rates $(P=0.002$ for both). Patients with high LDH levels had significantly lower DFS $(P=0.007)$. Treatment modality (surgical or conservative) had no impact on OS or DFS. The effects of clinical variables on five-year OS and DFS are given in Table 4.

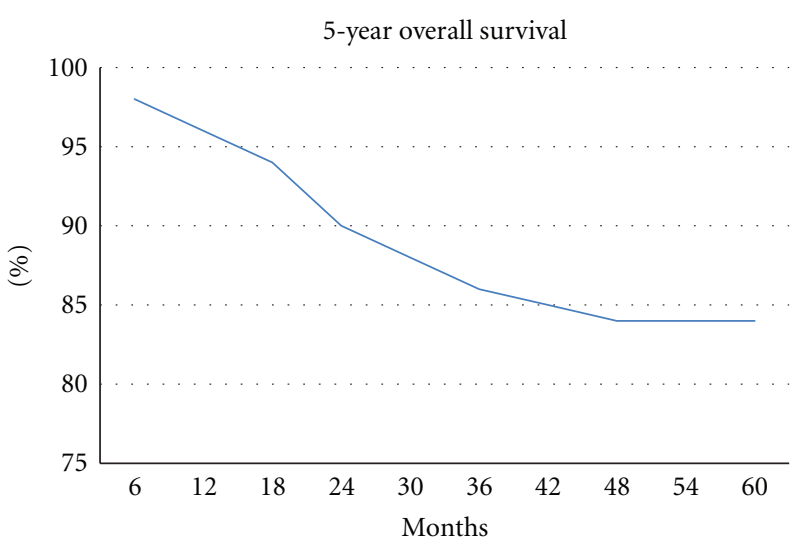

FIGURE 1: Kaplan-Meier curve for overall survival of 79 patients with PGL.

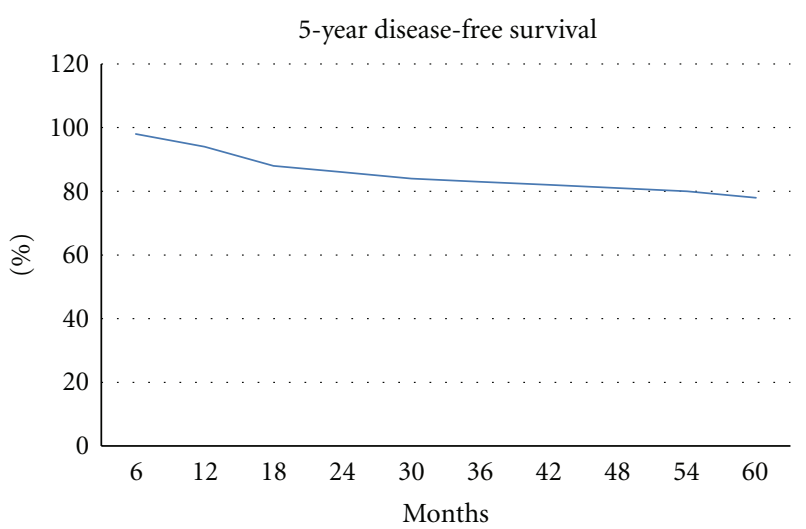

FIGURE 2: Kaplan-Meier curve for disease-free survival of 79 patients with PGL.

3.4. Multivariate Analysis for DFS and OS. Based on the results from the univariate analyses, we performed multivariate analyses using a Cox proportional hazard model (Table 5). Poor Karnofsky performance status, advanced stage, and high level of $\mathrm{LDH}$ were significant prognostic factors for DFS in the Cox model. Advanced stage, poor Karnofsky index, and age $>60$ years were significant prognostic factors for OS in multivariate analyses.

\section{Discussion}

PGLs represent more than half of all primary gastrointestinal lymphomas, accounting for 5\% of all malignant tumors of the stomach [9-12]. According to histological type, PGLs are divided into low-grade and high-grade. In this retrospective study, the rate of MALT lymphomas (21\%) was lower than previously shown $[4,5]$. About $40 \%$ of PGLs are low-grade lesions thought to arise in the mucosa from the defined MALT lymphoma, and $60 \%$ are histologically considered high-grade $[4,6,10]$.

Epigastric pain, epigastric discomfort, anorexia, weight loss, nausea, vomiting, and gastrointestinal bleeding were the most common symptoms in the present study, as reported 
TABLE 4: The clinical variables and their prognostic impact on five-year DFS and OS.

\begin{tabular}{|c|c|c|c|c|c|}
\hline & & DFS (\%) & $P$ value $^{\mathrm{a}}$ & OS (\%) & $P$ value ${ }^{\mathrm{a}}$ \\
\hline \multirow{2}{*}{ Gender } & Female & 76.4 & \multirow{2}{*}{0.7} & 84.1 & \multirow{2}{*}{0.6} \\
\hline & Male & 81.2 & & 81.9 & \\
\hline \multirow{2}{*}{ Age } & $>60$ & 77.9 & \multirow{2}{*}{0.4} & 75.5 & \multirow{2}{*}{0.04} \\
\hline & $\leq 60$ & 79.9 & & 89.8 & \\
\hline \multirow{2}{*}{$\mathrm{LDH}$} & $>240 \mathrm{mg}$ & 72.5 & \multirow{2}{*}{0.007} & 79.9 & \multirow{2}{*}{0.09} \\
\hline & Normal range & 86.8 & & 90.9 & \\
\hline \multirow{2}{*}{ Symptoms } & B symptoms present & 82.3 & \multirow{2}{*}{0.4} & 79.2 & \multirow{2}{*}{0.2} \\
\hline & B symptoms absent & 74 & & 88.6 & \\
\hline \multirow{2}{*}{ Lymphoma subtype } & MALT & 81.3 & \multirow{2}{*}{0.57} & 91.2 & \multirow{2}{*}{0.38} \\
\hline & Non-MALT & 76.9 & & 81.2 & \\
\hline \multirow{2}{*}{ Karnofsky index } & $\geq 80$ & 89.5 & \multirow{2}{*}{0.002} & 89.5 & \multirow{2}{*}{0.002} \\
\hline & $<80$ & 54.5 & & 63.6 & \\
\hline \multirow{2}{*}{ Stage } & I/II, IIE & 83.9 & \multirow{2}{*}{0.02} & 91.2 & \multirow{2}{*}{0.002} \\
\hline & IV & 65.5 & & 70.6 & \\
\hline \multirow{2}{*}{ Treatment (for stage I/II, IIE) } & Surgery & 85.7 & \multirow{2}{*}{0.18} & 86.5 & \multirow{2}{*}{0.8} \\
\hline & Conservative & 82.1 & & 94 & \\
\hline
\end{tabular}

${ }^{a}$ Long-rank test.

DFS: disease-free survival, OS: overall survival, LDH: lactate dehydrogenase, and MALT: mucosa associated lymphoid tissue.

TABLE 5: Multivariate analyses for DFS and OS.

\begin{tabular}{|c|c|c|c|c|c|c|c|}
\hline & & \multicolumn{3}{|c|}{ DFS } & \multicolumn{3}{|c|}{ OS } \\
\hline & & $\mathrm{RR}$ & $95 \% \mathrm{CI}$ & $P$ value & RR & $95 \% \mathrm{CI}$ & $P$ value \\
\hline \multirow{2}{*}{ Karnofsky index } & $\geq 80$ & 1 & \multirow{2}{*}{$1.5-10.9$} & \multirow{2}{*}{0.005} & 1 & \multirow{2}{*}{$1.6-11.2$} & \multirow{2}{*}{0.001} \\
\hline & $<80$ & 4.1 & & & 4.1 & & \\
\hline \multirow{2}{*}{ Stage } & I/II, IIE & 1 & \multirow{2}{*}{$1.2-1.9$} & \multirow{2}{*}{0.01} & 1 & \multirow{2}{*}{$1.5-9.7$} & \multirow{2}{*}{0.004} \\
\hline & IV & 1.4 & & & 3.8 & & \\
\hline \multirow{2}{*}{$\mathrm{LDH}$} & Normal range & 1 & \multirow{2}{*}{$1.05-1.63$} & \multirow{2}{*}{0.02} & & & \\
\hline & $>240 \mathrm{mg}$ & 1.18 & & & & & \\
\hline \multirow{2}{*}{ Age } & $\leq 60$ years & & & & 1 & \multirow{2}{*}{$1.15-1.9$} & \multirow{2}{*}{0.04} \\
\hline & $>60$ years & & & & 1.4 & & \\
\hline
\end{tabular}

RR: relative risk; CI: confidence interval, DFS: disease-free survival, OS: overall survival, and LDH: lactate dehydrogenase.

in other series $[4,13-15]$. In the current report, there was a slight male predominance $[4,13,14,16]$, while other studies reported female prominence among cases of PGL $[14,16]$.

In PGL, there are multiple factors that affect survival. In previous studies, advanced stage, poor performance status, age $>60$ years, and elevated $\mathrm{LDH}$ at presentation of the disease were associated with poor outcome; female sex, low-grade histology, good performance status, and surgical resection for local disease have been reported to be associated with high OS and DFS rates [4, 17-19]. In our study, the fiveyear OS and DFS rates were $83.1 \%$ and $78.6 \%$, respectively. In patients with stage I/II or IIE disease at presentation, the five-year OS and DFS rates were $91.2 \%$ and $83.9 \%$, respectively. The five-year OS and DFS rates of those with stage IV disease at presentation were $70.6 \%$ and $65.5 \%$, respectively. In prior studies, the survival rate of patients with PGL was 78-92\%, according to stage and treatment modality
[6, 19-22]. Based on our results, variables associated with poor DFS were advance stage, high $\mathrm{LDH}$ level, and poor performance status. In a multivariate analysis, variables associated with poor DFS were also advanced stage, high LDH level, and poor performance status. Regarding OS, a univariate analysis revealed that advanced stage, age $>60$ years, and poor performance status were associated with a poor prognosis. In the multivariate analysis, advanced stage, poor performance status, and age were associated with a poor prognosis.

There are no standard therapeutic guidelines for patients in whom antibiotic therapy has failed. In two retrospective studies of patients with MALT lymphoma, no significant differences in survival were found between different treatment modalities $[23,24]$. In our study, patients with MALT lymphoma were those in whom antibiotic therapy failed. No significant differences in DFS or OS were demonstrated 
among PGL patients who had nonsurgical or surgical treatment of the local disease (stage I/II or IIE) of MALT or non-MALT lymphoma. Controversy remains over the optimal treatment for early stages of PGL, particularly regarding the role of surgery. Historically, surgery has been used as the initial treatment for PGL [13]. Recently, it has become evident that there is no difference in survival rates for those who were treated with surgery compared to a conservative modality. Surgery is no longer accepted as the cornerstone treatment of PGL and is reserved for when nonsurgical treatment is not possible. Surgery should be considered following nonsurgical treatment and when disease complications, such as hemorrhage, obstruction, or perforation, have occurred [9]. However, it is well known that surgical approaches have a number of potential disadvantages. Mortality associated with surgery has been estimated at nearly $8 \%$ [25]. Additionally, significant morbidity is associated with gastrectomy, as follows: $17 \%$ of patients developed malabsorption syndromes, 38\% reported weight loss, and 13\% developed dumping syndrome [26]. On the other hand, of the patients who received chemotherapy, only $5 \%$ developed acute complications, such as gastric perforation and gastrointestinal hemorrhage [20, 27-30].

In the present study, there was no difference between conservative and surgical treatment approaches with regard to DFS and OS. The main limitations of this study were its retrospective design and the lack of data on patient quality of life and toxicities in patients treated with a conservative approach or surgery.

In conclusion, poor performance status, advanced stage of disease, high LDH level, and advanced age were bad prognostic factors for patients with PGL. Surgery provides no advantage for survival over conservative treatment; thus, conservative treatment modalities should be preferred initially at early stages of PGL. Further prospective, largescale, controlled studies are needed to determine the impact of different treatment modalities on the outcome of patients with PGL.

\section{References}

[1] S. Paryani, R. T. Hoppe, and J. S. Burke, "Extralymphatic involvement in diffuse non-Hodgkin's lymphoma," Journal of Clinical Oncology, vol. 1, no. 11, pp. 682-688, 1983.

[2] W. J. Loehr, Z. Mujahed, F. D. Zahn, G. F. Gray, and B. Thorbjarnarson, "Primary lymphoma of the gastrointestinal tract: a review of 100 cases," Annals of Surgery, vol. 170, no. 2, pp. 232-238, 1969.

[3] K. J. Lewin, M. Ranchod, and R. F. Dorfman, "Lymphomas of the gastrointestinal tract. A study of 117 cases presenting with gastrointestinal disease," Cancer, vol. 42, no. 2, pp. 693-707, 1978.

[4] P. Koch, F. Del Valle, W. E. Berdel et al., "Primary gastrointestinal non-Hodgkin's lymphoma: i. Anatomic and histologic distribution, clinical features, and survival data of 371 patients registered in the german multicenter study GIT NHL 01/92," Journal of Clinical Oncology, vol. 19, no. 18, pp. 3861-3873, 2001.

[5] G. Papaxoinis, S. Papageorgiou, D. Rontogianni et al., "Primary gastrointestinal non-Hodgkin's lymphoma: a clinicopathologic study of 128 cases in Greece. A Hellenic Cooperative Oncology Group study (HeCOG)," Leukemia and Lymphoma, vol. 47, no. 10, pp. 2140-2146, 2006.

[6] P. Koch, A. Probst, W. E. Berdel et al., "Treatment results in localized primary gastric lymphoma: data of patients registered within the German multicenter study (GIT NHL 02/96)," Journal of Clinical Oncology, vol. 23, no. 28, pp. 70507059, 2005.

[7] P. F. Ferrucci and E. Zucca, "Primary gastric lymphoma pathogenesis and treatment: what has changed over the past 10 years?" British Journal of Haematology, vol. 136, no. 4, pp. 521-538, 2007.

[8] N. L. Harris, E. S. Jaffe, J. Diebold et al., "World health organization classification of neoplastic diseases of the hematopoietic and lymphoid tissues: report of the clinical advisory committee meeting —airlie house, Virginia, November 1997," Journal of Clinical Oncology, vol. 17, no. 12, pp. 3835-3849, 1999.

[9] A. M. Al-Akwaa, N. Siddiqui, and I. A. Al-Mofleh, "Primary gastric lymphoma," World Journal of Gastroenterology, vol. 10, no. 1, pp. 5-11, 2004.

[10] D. L. Bartlett, M. S. Karpeh, D. A. Filippa, and M. F. Brennan, "Long-term follow-up after curative surgery for early gastric lymphoma," Annals of Surgery, vol. 223, no. 1, pp. 53-62, 1996.

[11] R. Ben-Yosef and R. T. Hoppe, "Treatment of early-stage gastric lymphoma," Journal of Surgical Oncology, vol. 57, no. 2, pp. 78-86, 1994.

[12] F. Brands, S. P. Mönig, and M. Raab, "Treatment and prognosis of gastric lymphoma," European Journal of Surgery, vol. 163, no. 11, pp. 803-813, 1997.

[13] S. B. Cogliatti, U. Schmid, U. Schumacher et al., "Primary B-cell gastric lymphoma: a clinicopathological study of 145 patients," Gastroenterology, vol. 101, no. 5, pp. 1159-1170, 1991.

[14] W. P. Schmidt, N. Schmitz, and R. Sonnen, "Conservative management of gastric lymphoma: the treatment option of choice," Leukemia and Lymphoma, vol. 45, no. 9, pp. 18471852, 2004.

[15] D. N. Weingrad, J. J. Decosse, and P. Sherlock, "Primary gastrointestinal lymphoma. A 30-year review," Cancer, vol. 49, no. 6, pp. 1258-1265, 1982.

[16] D. S. Shimm, D. E. Dosoretz, and T. Anderson, "Primary gastric lymphoma. An analysis with emphasis on prognostic facts and radiation therapy," Cancer, vol. 52, no. 11, pp. 20442048, 1983.

[17] S. S. Yoon, D. G. Coit, C. S. Portlock, and M. S. Karpeh, "The diminishing role of surgery in the treatment of gastric lymphoma," Annals of Surgery, vol. 240, no. 1, pp. 28-37, 2004.

[18] S. Nakamura, T. Matsumoto, M. Iida, T. Yao, and M. Tsuneyoshi, "Primary gastrointestinal lymphoma in Japan: a clinicopathologic analysis of 455 patients with special reference to its time trends," Cancer, vol. 97, no. 10, pp. 24622473, 2003.

[19] H. Medina-Franco, S. S. Germes, and C. L. Maldonado, "Prognostic factors in primary gastric lymphoma," Annals of Surgical Oncology, vol. 14, no. 8, pp. 2239-2245, 2007.

[20] A. Avilés, M. J. Nambo, N. Neri et al., "The role of surgery in primary gastric lymphoma: results of a controlled clinical trial," Annals of Surgery, vol. 240, no. 1, pp. 44-50, 2004.

[21] H. Brincker and F. D'Amore, "A retrospective analysis of treatment outcome in 106 cases of localized gastric nonHodgkin lymphomas," Leukemia and Lymphoma, vol. 18, no. 3-4, pp. 281-288, 1995.

[22] B. G. Taal, J. M. V. Burgers, P. Van Heerde, A. A. M. Hart, and R. Somers, "The clinical spectrum and treatment of 
primary non-Hodgkin's lymphoma of the stomach," Annals of Oncology, vol. 4, no. 10, pp. 839-846, 1993.

[23] G. Pinotti, E. Zucca, E. Roggero et al., "Clinical features, treatment and outcome in a series of 93 patients with lowgrade gastric MALT lymphoma," Leukemia and Lymphoma, vol. 26, no. 5-6, pp. 527-537, 1997.

[24] C. Thieblemont, C. Dumontet, F. Bouafia et al., "Outcome in relation to treatment modalities in 48 patients with localized gastric MALT lymphoma: a retrospective study of patients treated during 1976-2001," Leukemia and Lymphoma, vol. 44, no. 2, pp. 257-262, 2003.

[25] D. H. Roukos, C. Hottenrott, A. Encke, G. Baltogiannis, and D. Casioumis, "Primary gastric lymphomas: a clinicopathologic study with literature review," Surgical Oncology, vol. 3, no. 2, pp. 115-125, 1994.

[26] A. Aviles, J. C. Diaz-Maqueo, A. De la Torre et al., "Is surgery necessary in the treatment of primary gastric non-Hodgkin lymphoma?" Leukemia and Lymphoma, vol. 5, no. 5-6, pp. 365-369, 1991.

[27] N. Maisey, A. Norman, Y. Prior, and D. Cunningham, "Chemotherapy for primary gastric lymphoma: does inpatient observation prevent complications?" Clinical Oncology, vol. 16, no. 1, pp. 48-52, 2004.

[28] H.-T. Liu, C. Hsu, C.-L. Chen et al., "Chemotherapy alone versus, surgery followed by chemotherapy for stage I/IIE large-cell lymphoma of the stomach," American Journal of Hematology, vol. 64, no. 3, pp. 175-179, 2000.

[29] I. D. Fleming, S. Mitchell, and R. A. Dilawari, "The role of surgery in the management of gastric lymphoma," Cancer, vol. 49, no. 6, pp. 1135-1141, 1982.

[30] S. Sharma, S. Singhal, S. De et al., "Primary gastric lymphoma: a prospective analysis of 12 cases and review of the literature," Journal of Surgical Oncology, vol. 43, no. 4, pp. 231-238, 1990. 


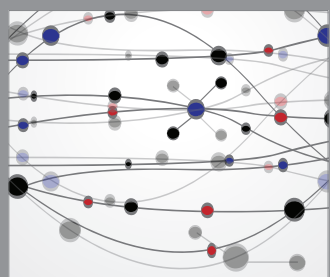

The Scientific World Journal
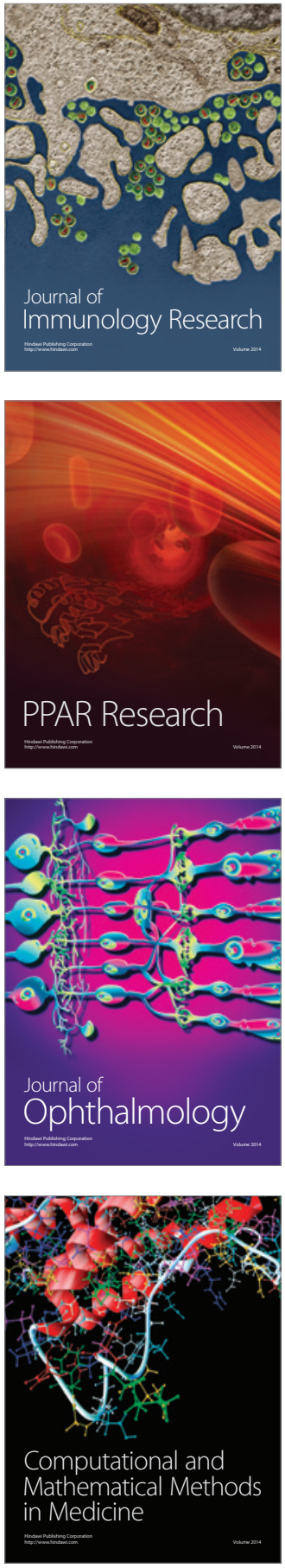

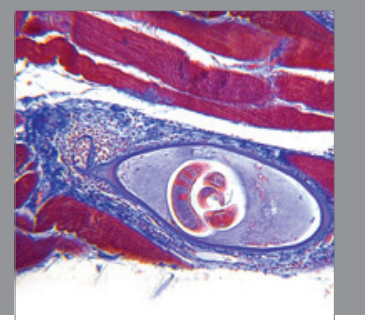

Gastroenterology

Research and Practice
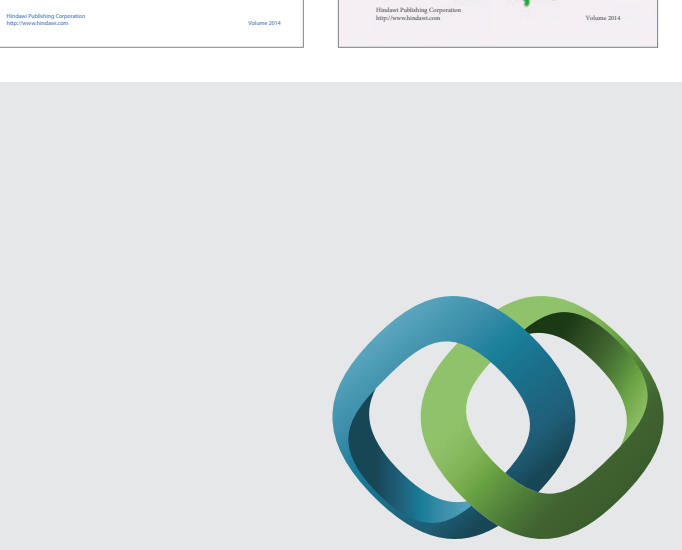

\section{Hindawi}

Submit your manuscripts at

http://www.hindawi.com
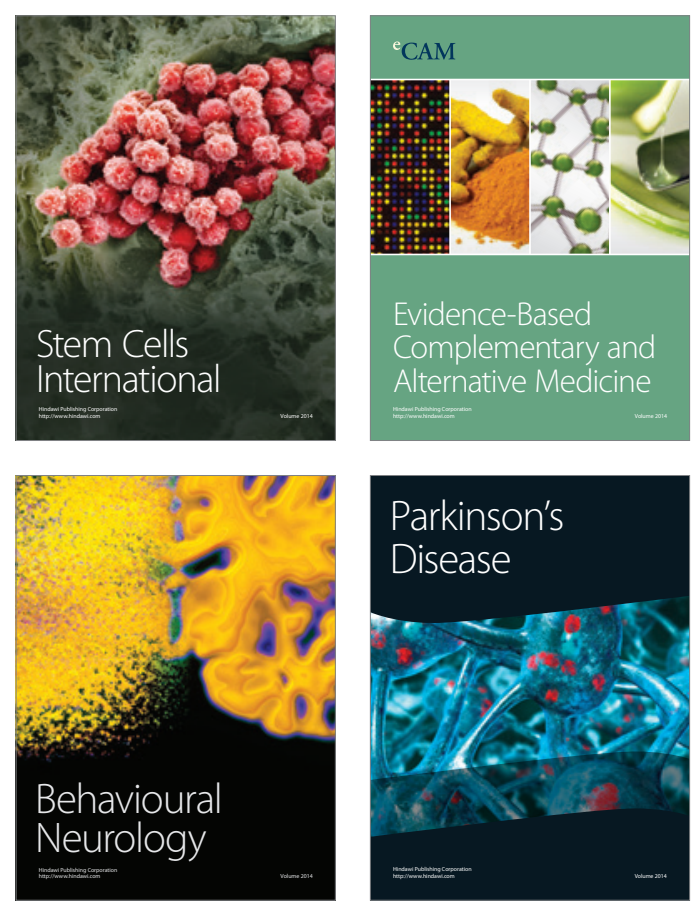

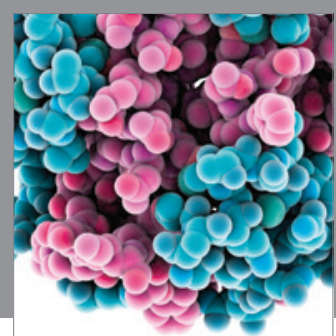

Journal of
Diabetes Research

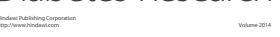

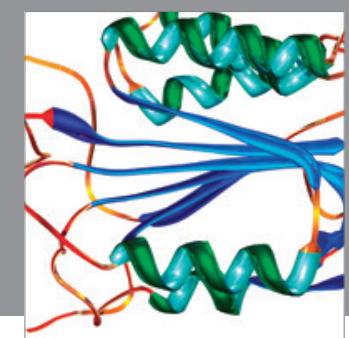

Disease Markers
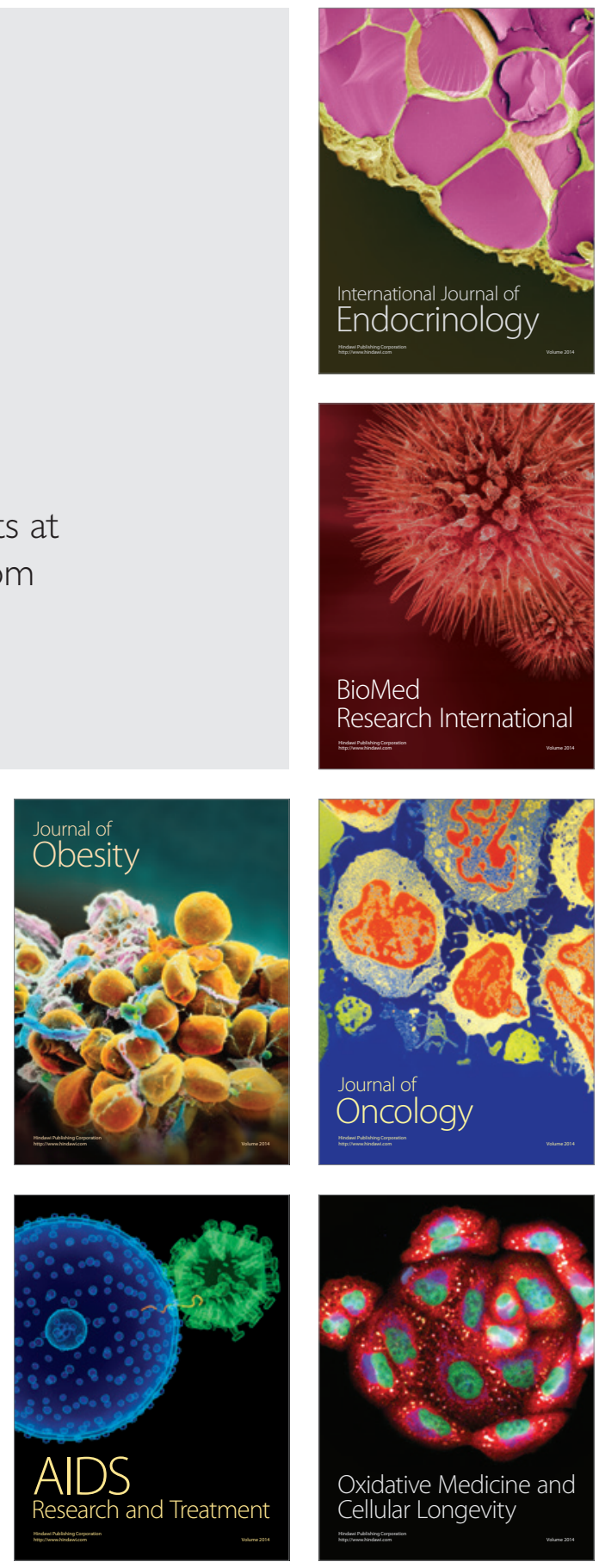